\title{
MUSEUS E MUSEOLOGIA EM PANORAMA
}

\author{
Rachel Vallego Rodrigues'
}

A recente publicação do livro de Dominique Poulot "Museus e Museologia" pela editora Autêntica vem suprir um vazio de traduções de obras deste autor no Brasil. Conforme comenta Maria Eliza Linhares Borges², na apresentação do texto, o livro foi sugerido para tradução pelo próprio autor após visita ${ }^{3}$ ao país em $201 \mathrm{I}$, especialmente por se tratar de um pequeno manual teórico sobre museus, que atende também a uma crescente demanda dos cursos de museologia e áreas afins no país.

Dominique Poulot é um historiador francês, professor na Sorbone (Paris-l) e pesquisador no Centre Nacional de la Recherches Laboratorie d'Antropologie et d'Historie de I'Institution de la Culture, especialista em museus e patrimônio histórico. Em "Museus e Museologia" apresenta um interessante mapeamento do caráter histórico dos museus, seu desenvolvimento e consolidação como campo de estudo, destacando aspectos de acervo e colecionamento, patrimônio cultural e preservação, além da busca por especialização dessas instituições, desde sua relação de autoridade intelectual até ao consumo turístico e a fidelização do público, sem deixar de mencionar o surgimento de novas tipologias de museus, como ecomuseus, e museus dedicados ao patrimônio imaterial. Faz também uma retrospectiva do desenvolvimento dos museus europeus, com um capítulo dedicado aos museus franceses e chegando a contemporaneidade aborda temáticas recentes como museografia, arquitetura dos museus e também aspectos do relacionamento com a indústria cultural.

O livro se apresenta dividido em seis capítulos divididos em tópicos, havendo destaque a alguns textos que aparecem como momentos de aprofundamento ou detalhamento do conteúdo principal. $O$ autor nos proporciona uma ampla visão das transformações dessas instituições no tempo, mantendo sempre como referência a perspectiva e o desenvolvimento dos museus europeus e principalmente dos museus franceses, de maneira que para o leitor brasileiro, em vários momentos, pode parecer uma realidade muito distante e desassociado das nossas próprias experiências e possibilidades.

No primeiro capítulo Poulot propõe uma retomada histórica do conceito de museu. Em referência ao conceito de templo da Grécia antiga como local de inspiração das musas, passando pela ênfase dada ao caráter de acumulo de riquezas intelectuais e sacralização do conhecimento, o conceito de museu tem um importante ponto de mudança com o surgimento do ICOM (Conselho Internacional de Museus) em 1946, que passa a propor normatizações de procedimentos e configura uma nova fase na elaboração das instituições. A conferência de 1972 no Chile une a dimensão social do museu na base formativa das políticas

\footnotetext{
I Mestranda do Programa de Pós-graduação em Arte da Universidade de Brasília com a pesquisa "A coleção do Banco Central e seu impacto nos museus brasileiros".

2 Professora colaboradora do Programa de Pós-Graduação em História da UFMG, Membro do Grupo de pesquisa "Elementos Materiais da Cultura e do Patrimônio".

3 Convidados como conferencista para a abertura do I* seminário Internacional Elementos Materiais da Cultura e do Patrimônio organizado pela Universidade Federal de Minas Gerais (UFMG) em 20II.
} 
museais, enquanto nova proposta de conceituação em 1974 é um marco, por oferecer uma visão ampla e concisa do que seria o papel dos museus no século $X X$.

O museu é uma instituição permanente, sem fins lucrativos, a serviço da sociedade e de seu desenvolvimento, aberta ao público e que faz pesquisas relacionadas com os testemunhos materiais do ser humano e de seu ambiente, tendo em vista a aquisição, conservação, transmissão e, principalmente, exposição desse acervo com a finalidade de estudo, educação e deleite (POULOT, 2013, p.18).

Complementado em 1986:"o museu deve se esforçar para assegurar que as informações fornecidas nas apresentações e exposições sejam honestas e objetivas, além de não perpetuarem mitos ou estereótipos." (POULOT, 2013, p. 18). Evidencia-se assim as cinco principais funções do museu: colecionar, conservar, estudar, interpretar e expor. $\bigcirc$ autor identifica a conservação como a ação determinante para o surgimento dos museus, por garantir a preservação do patrimônio nacional, enquanto o estudo e a pesquisa se tornam a finalidade das políticas de aquisição e exposição. Reforça a importância da publicação de catálogos para democratização e acessibilidade da informação sobre os acervos, notadamente quando pertencem a instituições públicas, e oferece destaque ao papel da comunicação, considerando a exposição o principal meio de contato com o público, é também por meio dela que se gera visibilidade aos estudos produzidos pelo museu. Em seu entendimento a exposição é uma manifestação temporária, na qual é possível aumentar a rotatividade do acervo exposto ao promover destaques, exposições monográficas ou temáticas que favorecem a imersão do visitante no conteúdo ofertado, expandindo ainda mais a atratividade do museu.

Alarga-se assim a gama de profissionais necessários para a criação de exposições e favorece-se o surgimento de novas profissões e empresas de museografia e expografia especializadas em criar exposições. Podemos rastrear desta forma o surgimento das exposições conhecidas como blockbusters, mega produções elaboradas para conquistar uma enorme quantidade de público e garantir visibilidade e prestígio ao museu. Entretanto o autor destaca que essa visibilidade nem sempre tem retorno a longo prazo para o museu, pois o caráter efêmero da exposição não garante a assiduidade posterior do público.

Neste sentido, é importante que o museu tenha clareza de sua missão e de como suas coleções permanentes orientam os projetos futuros, a estrutura administrativa da instituição e suas possibilidades de expansão, seja de seu acervo como também da estrutura arquitetônica disponível para este fim.

Apresenta-se em seguida um mapeamento da tipologia de museus dedicados a história das nações e de representação do espaço social. No segundo capítulo, Poulot observa um aumento na fundação de museus dedicados a temas específicos, como a história de um artista ou heróis do tempo, paralelamente a uma estabilização ou mesmo decréscimo de museus tradicionais de história, que buscavam a universalidade através da exposição de acervos abrangentes. Os museus dedicados a história das nações, focados em criar uma perspectiva identitária, de fervor patriótico perderam espaço no século $X X$ para museus de reconstituição, que oferecem uma mimese do tempo passado, uma imersão na história, ou, por outro lado, museus que proporcionam uma perspectiva futura que não se limita a uma estética de ressurreição mas também pensam a tecnologia e a interatividade. Dentro deste perfil podemos encontrar também sobre fundação de museus dedicados ao luto, as memórias do Holocausto e suas ten- 
tativas de reconciliação, entrando nessa categoria todos os museus dedicados ao registro e ao não apagamento de memórias contraditórias ou mesmo controversas. Há ainda os museus de cunho social, como os localizados em sítios históricos, como palácios e museus de etnografia nacional.

Já os museus dedicados a preservação da história urbana das cidades muitas vezes evocam com nostalgia a sua evolução, e procuram recriar cenários ou mesmo expor reconstituições em tamanho natural, como os museus a céu aberto que preservam integralmente construções e modos de vida tradicionais. Os ecomuseus por sua vez consideram a importância da preservação do meio ambiente em interação com a comunidade, que participa ativamente desse processo de tomada de consciência de salvaguarda de seu patrimônio ambiental. $\bigcirc$ autor destaca serem estes os primeiros museus pluridisciplinares, no qual a ação da população é uma peça fundamental para seu bom funcionamento.

Poulot prossegue no terceiro capítulo com considerações sobre o surgimento da ação de colecionar e expor pelo mundo. A origem dos museus e a abertura das coleções para acesso público marcam a época museus modernos, e a partir da Revolução Francesa estabelece como direito e necessidade do povo de ter acesso a cultura para poder conhecer e estabelecer laços identitários de sociedade. No século XIX o museu era visto como símbolo da nação, da coletividade que representa, responsável por manter a memória cultural e propagar um saber positivo, universalizaste, e favorecedor de vínculos sociais.

O autor destaca a Inglaterra, Alemanha e França como os principais "modelos em matéria de museu, graças à importância de seus acervos, à abertura de novos estabelecimentos e à qualidade de sua organização" (POULOT, 20 I 3, p. 64) e passa a descrever os caminhos tomados por estes países e museus para atestar sua afirmação, incluindo também em seu comentário alguns museus norte-americanos. A partir do século $X X$ tem-se uma guinada, seja pelo desejo de renovação do perfil de museu, na tentativa de abandonar a enfadonha noção de ser detentor de todo o conhecimento, seja pelos reflexos da guerra e o peso dos regimes totalitários que limitaram significativamente as possibilidades de expansão e reflexão crítica.

Enquanto num primeiro momento a preocupação museografia européia era voltada para a iluminação e com o sistema de dependurar peças, nos Estados Unidos os museus buscam uma museografia de contexto que chama a atenção não apenas para a tentativa de ilustração decorativa das obras, bem como a transferência massiva de bens e obras de arte da Europa.A preocupação com o público e incremento de atividades educativas para enriquecer a visita são características do período, sempre colocando em destaque a visibilidade e acessibilidade dos acervos.

O capítulo seguinte é totalmente dedicado a evolução francesa de museus e a sua intensa ligação com o Estado. Passando pela tradição dos salões de arte a Academia Real de Pintura e Escultura durante o século XVIII, evento considerado um dos maiores prestígios na carreira de um artista, durante o século XIX vai sofrer um crescimento exponencial tanto da quantidade de artistas aceitos quanto o aumento no número de visitantes. Inversamente decaem a qualidade das obras e do prestígio da própria instituição, questionada pela falta de critérios na seleção das obras, acaba por transformar-se em insignificante na formação dos artistas no seu desejo por reconhecimento. Em meados de 1880 o Salon é encerrado, considerando-se que foi gradativamente substituído pelo surgimento de diversas galerias particulares e marchands.

O papel do Estado volta a ser atuante após a primeira guerra, com a necessidade de elaboração de uma política cultural. Dá-se assim a criação do Ministério da Cultura, tendo como primeiro chefe da pasta o artista André 
Maulraux, que estabelece como objetivo o fortalecimento das iniciativas do Estado para promoção da cultura, da arte e do patrimônio. Novos museus são fundados, como o Centre Pompidou - Beaubourg, cujo projeto é de 1969, mas só será inaugurado em 1977. A meta de I\% do orçamento francês destinado as ações do ministério só vai conseguir ser atingida nos anos 1980.

Data de 2002 a lei sobre os Museus da França, definindo as frentes de atuação do Estado em relação ao patrimônio, educação e difusão. Evidencia-se a preocupação de tornar os bens artísticos inalienáveis, já que durante a Revolução Francesa promoveu-se uma política de devolução de bens e obras de origem estrangeira, visando restituir o sentido original e de legitimidade dessas obras. A criação da marca "Musée de France" registra os museus que alcançaram as três metas básicas, sendo elas a elaboração de um estatuto do museu, 0 inventariamento de todos os seus bens e a definição de um projeto cientifico e cultural que atue como direcionador do museu. $O$ autor enfatiza que "o principal desafio para as próximas décadas é o do lugar e do papel dos museus como atores e alavancas de desenvolvimento na recomposição das diferentes regiões." (POULOT, 20I3, p. I0I) tendo em mente considerar sempre a partir do estágio de desenvolvimento que os museus franceses já conquistaram.

O texto oferece uma visão ampla do desenvolvimento dos museus na França, mas por vezes parece apressado, pressupõe um certo domínio da questão que para o autor é extremamente comum e cotidiano. Mas para o leitor estrangeiro, as trocas de referências, por exemplo, no uso de datas no Calendário da Revolução Francesa ao mesmo tempo, por vezes no mesmo parágrafo, em que são usadas datas do Calendário Gregoriano (a contagem de anos tradicional) ou o uso de siglas sem especificar qual o nome da instituição tornam a leitura confusa.

O capítulo cinco nos oferece uma visão contemporânea dos museus, analisa as transformações do campo pela lente de alguns especialistas, alguns com um tom mais apocalíptico, prevendo a falência inerente ao sistema com a chegada da era da virtualidade, outros enxergam a necessidade de retorno ao material "como uma reação à ameaça de amnésia ou obsolescência acelerada" (POULOT, 20I3, p. I06) da vida contemporânea.A partir dos anos 1970 vive-se um momento de expansão museal, há um crescimento expressivo da quantidade de museus pelo mundo e o surgimento de grandes empreendimentos, como museus sucursais (por exemplo o Gugenheim abre filiais em diversos países) e um crescente flerte com a industria cultural de entretenimento e os parques temáticos.

O autor admite a instabilidade da instituição museu no cenário econômico, político e tecnológico atual e a necessidade adaptabilidade para manter suas portas abertas reflete na mudança de políticas, no reconhecimento da importância do público que passa a ser cada vez mais valorizado e colocado no centro das decisões. Tornar o museu um espaço social e coletivo, no qual a visitação se dá muito mais em grupos do que visitantes sozinhos, e uma premente necessidade de inclusão social de grupos que antes eram totalmente alheios ao museu desencadearam grandes mudanças no perfil dos museus e em como eles querem se projetar para a sociedade. Nesse sentido a arquitetura ganha destaque nos novos museus, que se dedicam a elaboração de um espaço que seja atrativo e versátil prioritariamente, da mesma forma que o projeto do museu ser assinado por um arquiteto importante se torna um fator de destaque e visibilidade.

Por fim, o capítulo 6 é dedicado a museologia como campo de estudos, ressaltando a necessidade de profissionalização e os desafios contemporâneos impostos à área, o autor faz um breve histórico da profissão. Cito o comentário de Wittlin que reflete sobre o desenvolvimento dos museus em três fases: 
A era clássica dos museus se apóia na centralização, nas especialização e na classificação das coleções, mas assiste também à primeira preocupação com o público. $O$ período entre as duas guerras se satisfaz com uma temática da educação que define a ambição dos novos museus e, ao mesmo tempo, suscita oposições declaradas. Enfim, os anos posteriores à guerra são um momento "de busca e de conflito, de gestação e de realizações, tal como os museus nunca haviam conhecido (WITTLIN, 1970 apud POULOT, 2013, p. 136)

$\mathrm{Na}$ contemporaneidade os museus estão intrinsecamente conectados com o desafio de atualização constante ao mesmo tempo detentores da tarefa de preservar as memórias da humanidade. $O$ papel legitimador que os museus exercem sobre a história, as produções sociais e culturais tem cedido espaço para a "experiência vivida, a memória do corpo e dos sentidos" (POULOT, 2013, p. I44), que são transformadoras e transformadas pelo mundo contemporâneo. Nas palavras de Poulot:

para se manterem pertinentes e atuais, os museus devem tomar cuidado com a amnésia dos lugares, dos homens e coleções; a atualização de seus sucessivos remanejamentos é uma tarefa que equivale à promessa de lucidez quanto à sua reivindicação obstinada de autenticidade (POULOT, 2013, p.I43).

Enquanto espaço de troca de saberes, o museu tem muito a ofertar, pela possibilidade de rememoração e renovação do conhecimento para as novas gerações, mantendo vivas as tradições e experiências de outros tempos, ao mesmo tempo em aberto para as conquistas futuras.

Poulot nos oferta com este livro uma excelente introdução ao estudo dos museus e da museologia, colocando em panorama as diversas experiências que construíram este campo de estudo até o momento. É um livro indicado aos estudantes universitários que desejem conhecer o complexo mundo dos museus. Mantendo o diálogo, sem ser superficial de mais nem muito específico, proporciona um quadro amplo da perspectiva européia, de tradição secular até alcançar o desenvolvimento contemporâneo e permite situar o leitor no estado da arte dos museus.

\section{Referência}

POULOT, Dominique. Museus e museologia.Tradução Guilherme João de Freitas Teixeira. Belo Horizonte:Autentica Ed., 2013. (Coleção ensaio geral).

Artigo recebido em maio de 2013. Aprovado em agosto de 2013 